\title{
Cem ZORLU, Abbasilere Yönelik Dinî ve Siyasî İsyanlar: Ebû Cafer el- Mansur Dönemi
}

(Ankara: Ankara Okulu Yayınları, 2001), 343 sayfa. ISBN: 9789758190386.

\author{
Mustafa Yanç \\ Arş. Gör., Bursa Uludağ Üniversitesi, İlahiyat Fakültesi, \\ İslam Tarihi ve Sanatları Ana Bilim Dalı \\ Bursa/Türkiye \\ mustafayanc@uludag.edu.tr \\ http://orcid.org/0000-0002-7960-1655
}

Emevîlere karşı Muhammed b. Ali ile başlatılan Abbâsî daveti, ardından onun oğlu İbrahim tarafından devam ettirilmiş, nihayet diğer bir oğlu olan Ebu'l-Abbâs esSeffâh'ın Kûfe şehrinde Abbâsî ailesi adına biat almasıyla birlikte amacına ulaşmıştır. Ebu'l-Abbâs ile filizlenmeye başlayan devlet onun dört yılllk hilafet döneminde öncelikle Emevîlerin hatırasını kanlı bir şekilde silmiştir. Bu dönemde devleti sarsacak veya varlığını tehdit edebilecek boyutlarda isyanlarla karşıllaşılmamıştır. Ebu'lAbbâs'in vefatıyla birlikte halifeliği üstlenen Ebû Cafer el-Mansûr ilk olarak isyan hareketleriyle karşı karşıya kalmıştır. Yirmi yıllık halîfeliği döneminde irili ufaklı pek çok isyan hareketiyle uğraşmak zorunda kalan Mansûr, mezkûr başkaldırıların tamamından galibiyetle ayrılması, yine devletin temellerini sağlamlaştırması sebebiyle Abbâsîlerin asıl kurucusu olarak kabul edilmiştir. Dolayısıyla Mansûr gibi bir halîfeyi tanıtacak, ayrıca döneminin belirgin özelliklerini ve hadiselerini tasvir edecek eserlere ihtiyaç vardır. Cem Zorlu'nun doktora tezi olarak hazırlanmış bu kitabı Ebû Cafer el-Mansûr dönemi isyanlarını etraflıca konu edinmektedir.

Çalışmanın “Önsöz"ünde takip ettiği metot ve istifade edilen kaynaklar hakkında bilgi veren Zorlu'nun araştırması "Giriş" ve beş bölümden oluşmaktadır. "Giriş"i üç başlık altında inceleyen müellif öncelikle "Abbâsî Daveti Döneminde İslâm Alemi”ni

Geliş Tarihi/Received Date: 05.05.2021

Kabul Tarihi/Accepted Date: 18.05.2021

Kitap Değerlendirmesi/Book Review

Atıf/Citation: Yanç, Mustafa. "Abbâsîlere Yönelik Dinî ve Siyasî İsyanlar: Ebû Cafer el-Mensûr Dönemi, Cem Zorlu, Ankara: Ankara Okulu Yayınları, 2001. 343 sayfa”. Uludağ Üniversitesi İlahiyat Fakültesi Dergisi 30/1

(Haziran 2021), 317-326. https://doi.org/10.51447/uluifd.933393 
farklı yönleriyle tanıtmıştır. Dönemin siyasî sınırları ve devleti oluşturan etnik unsurları kısaca tasvir edilmiş, sosyal ve ekonomik yapıdan bahsedilmiş, son olarak ta devlet sınırları içerisinde barınan siyasî ve dinî akımlar tanıtılmıştır. "Giriş" bölümünün ikinci kısmında ise Abbâsî Daveti'nin gizli ve alenî faaliyetlerine yer verilmiştir. Son kısımda ise davetin başarıya ulaşmasıyla birlikte halîfe seçilen Ebu'l-Abbâs esSeffâh'ın dönemi özetlenmiştir. "Giriş” bölümün yapısı incelediğinde müellifin buradaki amacının, araştırmanın asıl konusu olan Mansûr dönemi olaylarının daha iyi anlaşılabilmesini sağlamak olduğunu ifade etmek mümkündür.

Cem Zorlu kitabının birinci bölümünde Abbâsî devletinin bünyesinde görev almış olan vali ve komutanların isyanlarını konu edinmiştir. Bu isyanların en önemlisi şüphesiz Abdullah b. Ali'nin iktidar mücadelesidir. Zira Abdullah ilk iki Abbâsî halifesinin amcaları olmakla Abbâsî ailesine mensuptur. Dolayısılla bu isyan Abbâsîlerin kendi içlerindeki ilk mücadele olması hasebiyle önem arz etmektedir. Müellif, Abdullah'ın isyanının esas sebebi olarak kendisine vaat edilen veliahtlık kararının iptaline işaret etmektedir. Çünkü o son Emevî halifesi Mervan b. Muhammed'e karşı mücadele etmiş, Emevîlerin yıkılmasında aktif rol almış ve netice olarak ta kendisine veliahtlık sözü verilmiştir. İlk halîfe Ebu'l-Abbâs'ın vefatından sonra bu sözün tutulmadığını sefer esnasında haber alan Abdullah b. Ali komutanı olduğu ordusuyla birlikte isyan etmiştir. Tahta çıkan yeğeni Mansûr ise Abbâsî ihtilâlinin lideri konumundaki Ebû Müslim'i onunla savaşmak üzere görevlendirmiştir. Cem Zorlu Mansûr'un bu görevlendirmesini onun klasik tasfiye stratejisi ile açıklamaktadır. Ebû Müslim'den haz etmeyen ve onu kendi iktidarı için büyük bir tehlike olarak gören halîfe, böylece iki düşmanını karşı karşıya getirmiştir. Başarılı bir komutan olan Ebû Müslim uyguladığı savaş stratejileri ile kendisinden çok daha üstün olan bir orduyu mağlup etmeyi başarmıştır.

Müellif kısa bir dönem sonra halîfe tarafindan ele geçirilip hapsedilen Abdullah'ın akıbeti hakkında açıklayıcı değerlendirmelerde bulunur. Halîfe Mansûr amcası Abdullah'ı ancak iktidarını sağlamlaştırdıktan sonra tasfiye edebilmiştir. Abdullah'ın temelinde tuz madeni bulunan bir evde tutsak edildiğini ve meskenin temeline akıtılan su sebebiyle yıkılması sonucu hayatını yitirdiğini kabul eden kaynakların aksine müellif, İbn Kuteybe'nin tek kaldığı bir rivayetten yola çıkarak binanın temelinin kerpiçten imal edildiğini belirtmiş ve bu görüşünü savunmuştur. Zorlu, Abdullah b. Ali'nin isyanını sistematik başlıklar (İsyanı Hazırlayan Sebepler, Başkentte Durum, Abdullah b. Ali Cephesi, Savaş, Abdullah'ın Kaçışı ve Hapsi, Abdullah'ın Öldürülmesi, İsyanın Başarıya Ulaşmasının Sebepleri, İsyanın Neticeleri, Değerlendirmeler) altında ele almış ve böylece meselenin zihinlerde daha iyi canlanabilmesini sağlamıştır. Bu başlık kullanımı eserin tamamında muhafaza edilmiştir.

Birinci bölümün ikinci kısmında komutan Cevher b. Merrâr el-i̇clînnin isyanı ele alınmıştır. Cevher, Ebû Müslim'in öldürülmesinden sonra Horasan'da patlak veren bir isyanı bastırmak üzere halîfe tarafından görevlendirilmiştir. 0 isyanı başarılı bir 
şekilde bastırdıktan sonra elde ettiği ganimetlerin tamamını kendisiyle birlikte mücadele etmiş olan askerlerine dağıtmıştır. Kaynakların verdiği bilgilere göre bu olayın ardından halîfe ile arası açılan Cevher kendi yerine tayin edilen valiyi öldürerek isyanı başlatmıştır. Merkezden gelen ordu tarafından tutuklanan Cevher Mansûr tarafından etkisiz hale getirilmiştir. Cem Zorlu, Mansûr ile Cevher'in arasındaki bu çatışmaya sadece ganimet dağıtımının sebep olamayacağını belirttikten sonra asıl sebebinin Cevher'in elde ettiği nüfuz olduğunu belirtmiştir. Zira Mansûr devletin ve tahtın bekasını tehdit edebilecek her türlü şahsı tasfiye etmiş ve itibarsızlaştırmıştır.

Bu bölümün üçüncü alt başlığında Abdülcebbâr b. Abdurrahman el İclî̀nin isyanı konu edinilmiştir. Abdülcebbâr Abbâsîi Ihtilali döneminde mücadele eden meşhur komutanlardan Kahtabe'nin ordusunda bulunmuş, kendisi aynı zamanda Abbâsî propagandasını yayan davetçilerden olmuştur. Horasan bölgesine vali tayin edildikten sonra bölgeyi hakkıyla yöneten Abdülcebbâr kendisinin yerinde gözü olan Polis Şefi Müseyyeb b. Züheyr tarafından bir hile ile görevinden uzaklaştırılmaya çalışılmıştır. Müseyyeb'in kendisini kandırdığını anlamayan Abdülcebbâr'ın halîfe ile arası açımıştır. Abdülcebbâr halîfeye durumu izah etmeye çalışsa da bu isteği reddedilmiş ve kendisine karşı merkezden bir ordu gönderilmiştir. Fakat ordunun müdahalesine gerek kalmadan Abdülcebbâr askerleri ve bölge ahalisi tarafından teslim edilmiş ve sonrasında cezalandırılmıştır. Müellif Abdülcebbâr'ın başarısız olması hakkında bazı yorumlarda bulunmuştur. Abdülcebbâr isyana kalkıştıktan sonra halkın desteğini alamamıştır. Kendi askerleri tarafından da yalnız bırakılan Abdülcebbâr farklı bölgelerde bulunan isyancılardan da beklediği desteği alamayınca kaderine teslim olmuştur.

Vali ve komutanların isyanlarının konu edinildiği bu bölümün son başlığında Uyeyne b. Musâ'nın isyanı ele alınmıștır. Müellifin verdiği bilgiye göre Uyeyne Abbâsî daveti propagandacılarından olup son Emevî halifesi Mervan'a karşı savaşan orduda komutan olarak görev yapmıştır. Babası Musâ b. Ka'b ise nakiplerden olmakla birlikte Ebu'l-Abbâs'a ilk biat edenler arasında idi.

Uyeyne babasının yerine vekâleten yürüttüğü Sind valiliğine onun vefatından sonra asaleten atanmıştır. Fakat Kuzey ve Güney Araplarının arasındaki dengeyi muhafaza edemediği için bölgede kargaşa ortamının baş göstermesine sebep olmuştur. Huzursuzlukların daha da büyümesinden endișe eden Mansûr'un olayların bir an önce sükûnete kavuşturulması için komutan Ömer b. Hafs'ı beraberinde bir ordu ile birlikte Sind bölgesine göndermesine rağmen Uyeyne, Ömer'in yönetimi üstlenmesine müsaade etmek bir yana onun şehre girmesine de engel olmuştur. Ömer'in 11 aylık kuşatmasından sonra teslim olan Uyeyne halîfeye gönderildiği esnada affedilmeyeceği endişesiyle Sicistan bölgesine kaçmıştır. Fakat Sicistan bölgesinde bulunan Kuzey menşeli Araplar onu yakalamış ve valiliği döneminde kendilerine reva gördüğü zulümlerden dolayı katletmişlerdir.

Çalışmasının ikinci bölümünde "İran Kökenli İsyanlar” ele alan Zorlu öncelikle bu bölgede gerçekleşen isyanların ortak özelliklerini ve isyancıları fiillerine sevk 
eden faktörleri ortaya koymuştur. İsyancı liderlerinin, İslâmî doktrinin yanında eski İran dinlerinin de görüşlerini benimsemiş olmalarını isyanın taban desteğini genişletme arzusu ile açıklayan müellif, liderlerin kendilerini kurtarıcı olarak vasıflandırdıklarını ve hareketlerini Ebû Müslim ile ilişkilendirdiklerini savunmuştur. Yazar isyan hareketlerini motive eden amiller arasında alt tabakanın yerel yöneticilerin adaletsiz uygulamalarından hoşnut kalmadığını, henüz Abbâsî yönetimine girmiş olan İranlı emirlerin Arap-İslâm hâkimiyetine karşı direnmelerini ve Emevîlerin tenkit edilen bazı uygulamalarının Abbâsî döneminde de devam ettirildiğini zikretmiştir.

İran kökenli isyancıların ilki olan Sünbâz Abbâsî daveti esnasında liderlerden Ebû Müslim ile tanışmış ve onunla kurduğu bağ sayesinde ordu komutanlığına kadar yükselmiştir. Müellifin verdiği bilgiye göre Sünbâz'ın isyanı dinî, sosyal ve siyasal sebeplere dayanmaktadır. O, Ebû Müslim'in intikamını almakla birlikte Sâsânî devletini ve Mecûsîliği tekrardan diriltmeyi hedefliyor ve böylece alt tabakanın beklentilerine cevap verebilmeyi umuyordu. Nişâpûr'da isyanı başlatan Sünbâz kısa bir dönemde Rey'e ve ardından Mâverâünnehr bölgesine hâkim olmuştur. Hâkimiyeti altında yaşayan Araplara her türlü zulmü reva gören isyancı lideri ekonomik açıdan önemli oldukları sebebiyle Müslüman-Arap tacirlerine karşı kayıtsız kalmıştır.

Cevher b. Merrâr el-İclî komutasında merkezden gönderilen ordu eliyle mağlup edilen Sünbâz Taberistan kralı Hurşîd'e sığınmıştır. Fakat Sünbâz'ın kendisini karşılamak için gönderilen kralın amcaoğlu Tûs'a karşı kibirli tavırlarda bulunması onun tarafından öldürülmesine sebep olmuştur. Amcaoğlunun bu fiilini tasvip etmemesine ve ziyadesiyle öfkelenmesine rağmen Hurşîd halîfe Mansûr ile arasını iyi tutabilmek için sonunda Sünbâz'ın kesik başını hilâfet merkezine göndermiştir.

İsyanın seyri ve sonucu hakkında değerlendirmelerde bulunan müellif isyanın geniş kitlelere ulaşmasını bölge halkının Ebû Müslim'e olan bağlılığı ile izah etmiştir. Sünbâz'ın Sâsânî devletini ve Mecûsîliği canlandırmayı taahhüt etmesiyle etrafına kalabalık bir kitleyi toplayabilmesi ise bölge halkının eski din ve devletlerine olan özlemleri ile açıklanmıştır.

Bölgede cereyan eden diğer bir isyan hareketi İshâk et-Türk liderliğinde gerçekleşmiştir. İshak, Ebû Müslim tarafından Orta Asya Türklerine propagandacı olarak gönderilmiştir. Bir rivayete göre ismindeki "Türk" nisbesi buraya dayanmaktadır. Onun Yahya b. Zeyd b. Ali'nin oğullarından olduğu söylense de, bu görüş İshâk'ın ortaya koyduğu doktrin göz önünde bulundurulduğunda pek mümkün gözükmemektedir.

Ebû Müslim'in Zerdüşt Peygamberi olduğu görüşünü savunan İshâk'1n isyana kalkışmasının sebeplerine dair kaynaklarda herhangi bir bilgi verilmediğini savunan Zorlu, kargaşa ortamını ortaya çıkaran sebeplerin Sünbâz'ınkiler ile benzerlik arz ettiği tahmininde bulunmuştur. İshâk'ın faaliyetleri bölge valisi Halid tarafından etki- 
siz hale getirilmiş ve arta kalan bazı isyancılar o dönemde isyan etmiş olan vali Abdülcebbâr'ın saflarına katılmışlardır. İshâk et-Türk'ün taraftarlarının XII. yüzyıla kadar Belh şehrinde yaşadıkları rivayetlerde yer edinmektedir.

İran kökenli isyanların üçüncüsü olan Râvendiyye isyanı mahiyeti itibariyle diğer isyanlardan ayrılmaktadır. Zira bu isyan silahlı mücadeleden ziyade kendini fikrî arenada göstermiştir. Râvendiyye'nin "Keysâniyye" ile eşit anlamda kullanıldığını savunan müellif bu grup hakkındaki muhtelif görüş ve hizipleşmeleri kısaca açıkladıktan sonra fırkanın Ebû Müslim'in intikamını almak amacıyla ortaya çıtığını savunan görüşü ele almaktadır. Râvendiyye fırkasının Ebû Müslim'in ölümünden önce ortaya çıktığını, yine Mansûr'u ilah edindiklerini, ayrıca isyanın Bağdat'ın kuruluşundan önce vuku bulduğunu, dolaysıyla rivayette belirtildiği gibi Bağdat'ta gerçekleşmiş olamayacağını zikreden Zorlu, Dineverî nin bu konuyla alakalı görüşünü eleştirmiştir.

Halîfe'yi ilah edinmiş olmalarına rağmen onun tarafından takibe uğramaları neticede Râvendiyye'nin onu ilahlıktan azletmesi ve isyanı ile sonuçlanmıştır. Başkent Hâşimiyye'deki mahkûmları serbest bırakan Râvendiyye mensupları ardından halifenin sarayını kuşatma altına almışlardır. Halîfe'nin ve tecrübeli komutan Ma'n b. Zâide'nin özel gayretleriyle kaçmakta olan halkın isyancılara karşı cesaretlendirilmeleri, neredeyse Mansûr'un hayatına mal olan isyancıların sonunu getirmiştir. Cem Zorlu halîfe Mansûr'un bu olaydan sonra başkent sakinlerine karşı olan güvenini yitirdiğini belirtmiş ve bu isyanın başkent Bağdat'ın kurulmasının sebeplerinden olduğunu ifade etmiştir.

$\mathrm{Bu}$ bölümün son isyanı Horasan ordusu içerisinde önemli bir konum elde etmiş olan Üstâzsîs isyanıdır. Rivayetlerde Abbâsî halîfelerinden Me'mûn'un anne tarafından dedesi olarak ta zikredilen Üstâzsîs bir rivayete göre elinde bulundurduğu bir maden sebebiyle, diğer bir rivayete göre ise halîfe Mansûr'un oğlu olan Mehdînin veliahtlığını kabul etmemesiyle devletle ters düşmüştür. Zorlu ise rivayetlerde geçen bu iki rivayeti birleştirmeyi tercih etmiştir. Ona göre Üstâzsîs elinde bulundurduğu maden sebebiyle merkezle ters düşmüş ve buna binaen de Mehdînnin veliahtlığını kabul etmemiştir.

İsyan eden Üstâzsîs'in 300 bine ulaşan destekçilerinin neredeyse tamamı yoksul çiftçilerden oluşmaktaydı. Hâzım b. Huzeyme komutanlığındaki halîfe ordusu etraflarına hendek kazarak bu kalabalıktan korunmaya çalışmışlar ve isyanı güçlükle bastırmışlardır. Mağlup olan Üstâzsîs merkeze gönderildikten sonra ölümle cezalandırilmışıır.

Müellif hareketin bastırılmasından sonra bölgenin Mansûr döneminde sükûnete erdiğini zikretmiş ve bu isyanın ekonomik sebeplerden dolayı baş gösterdiğini ifade ederek diğerlerinden farkına işaret etmiştir.

Araştırmanın üçüncü bölümünde Hâricî isyanlarını çalışmanın diğer kısımlarında alışı olunmadığı üzere bölgeler (Cezîre, Umân, Yemen, Bahreyn ve Yemâme, 
Horâsân ve Sicistan, Kuzey Afrika) halinde ele alan müellif isyanların en yoğun yaşandı̆̆ı Cezîre bölgesi ile söze başlamıștır.

Abdullah b. Ali'den sonra bölgede gelişen en ciddi hareket olan Mülebbed b. Harmele eş-Şeybânî isyanı Horâsânlı bazı askerlerin evine misafir oldukları sırada yaşanan olaylar neticesinde patlak vermiştir. Rivayetlere göre Horâsânlı komutan Mülebbed'in hane halkından olan bir kadından başını yıkamasını istemiş ve isteği gerçekleştirilmediği gibi Mülebbed tarafından katledilmiştir. Zorlu Hâricîlerin çok basit bir sebeple isyana kalkıştıklarını, dolayısıyla uzun zamandır harekete geçmeyi düşündüklerini ve bu olayın bardağı taşıran son damla olduğunu ifade etmiştir.

Müellifin tespitlerine göre Mülebbed'in ilk etapta halîfe ordularına galip gelmesinin sebepleri arasında merkezî hükümetin o dönemde Sünbâz isyanı ile meşgul olması, yine Hâricîlerin zalim sultana başkaldırmayı dinî bir doktrin olarak addetmeleri sebebiyle bu uğurda her şeylerini ortaya koyarak savaşmaları ve manevra kabiliyeti yüksek olan bir birlik ile halîfe ordularına karşı koymaları zikredilebilir. Fakat Sünbâz'nn mağlup edilmesinden sonra ordunun toplanması, ordu komutanı Hâzım b. Huzeyme'nin Mülebbed'in gerilla taktiğine müsaade etmeyecek hamlelerde bulunması, Mülebbed'in elde ettiği bölgelerde kendi otoritesini sağlamlaştırmaması ve halîfe Mansûr'un isyanları bastırma konusundaki inatçı tavrı Mülebbed'in sonunu hazırlamıştır.

Cem Zorlu Mülebbed'in isyanından çıkarılabilecek sonuçlar arasında Hârîcîlerin basit sebeplerden dolayı her an isyan edebileceklerinin ve devletin bunlara karşı daima teyakkuz halinde bulunması gerektiğinin Mansûr tarafından anlaşıldığını zikretmiş, Hârîcilerin Emevî devletine karşı duydukları nefretin aynısını Abbâsîlere karşı da hissettiklerini savunmuştur.

Cezîre bölgesinde vuku bulan isyanları Atıyye b. Ba'ser et-Tağlibî, Hassân b. Gassân el-Hemedânî ve Hassân b. Mücâlid isyanlarına da kısaca yer vererek noktalayan müellif Umân bölgesinde herhangi bir isyana rastlanmadığını belirtmiştir. Ardından Yemen, Bahreyn, Yemâme, Horâsân ve Sicistan bölgelerindeki Hâricî isyanlarına kısaca değinen Zorlu, Kuzey Afrika isyanlarını bölgede görev yapmış olan valilerin dönemlerine göre tertip ederek araştırmanın üçüncü bölümünü sonlandırmiştır.

Cem Zorlu “Şiî Karakterli İsyanlar” başlığı altında kaleme aldığı dördüncü bölümde öncelikle mezkûr fırkanın Mansûr dönemine kadar geçirdiği evreyi açıklamaktadır. Ardından Ebvâ'da gerçekleştiği iddia edilen toplantıda Muhammed b. Abdullah'ın lider seçildiği savunulmuşsa da Zorlu bu tür iddialara şüphe ile yaklaşmaktadır. O Abbâsî davetinin Muhammed b. Ali liderliğinde Ebvâ'daki toplantıdan bağımsız ve çok önceleri başlatıldığını savunmuş, dolayısıyla Muhammed b. Abdulah'ın lider seçilmiş olamayacağını ifade etmiştir. Ayrıca Muhammed'in isyanı sırasında Mansûr ile arasında geçen mektuplaşmalarda lider oluşundan ve Ebvâ toplantısından bahsetmemesi toplantının vuku bulmadığı hakkında delil sayılmıştır. 
Muhammed b. Abdullah'ın ve Alioğulları'nın ilk Abbâsî halifesi Ebu'l-Abbâs dönemindeki tutumlarını açıkladıktan sonra onların Mansûr dönemindeki durumlarından ve halîfe ile aralarındaki ilişkilerden bahseden Zorlu, Muhammed'in isyanını ilanı hakkında açıklamalarda bulunmuştur. Müellife göre Muhammed kendisini halifeliğe Abbasoğulları'ndan daha layık görüyordu ve isyanının esas sebebi bu amile dayanmakta idi. Muhammed b. Abdullah İmam Malik'in de cevaz verdiği isyanı Medine'de başlatmıştır. Fakat Medine mezkûr faaliyet için uygun şartları sağlamıyordu. Zira burası Hz. Ali'nin hilafeti ile birlikte yönetim merkezi olma vasfını kaybetmiş, ilim ve kültürün başkentine dönüşmüştür. Dolayısıyla Medine ahalisinin kalem tutan elleri ile merkezî orduya karşıllı vermek mümkün değildir. Ayrıca dönemin Medine'si erzağını dışarıdan temin ediyordu. Bu duruma vakıf olan halîfe isyancıların erzak yollarını kesmiş ve onları zor durumda bırakmayı hedeflemiştir.

Dönemin veliahdı İsâ b. Musâ komutanlığında merkezden yola çıkan halîfe ordusunun Medine'ye ulaşmasından önce Muhammed okuduğu bir hutbe esnasında bölgeyi terk etmeleri hususunda şehir ahalisini serbest bırakmıştır. İnsanların etrafından dağılması sonucunda Muhammed'in taraftarları 313 kişi ile sınırlı kalmıştır. Medine'nin etrafını saran İsâ Muhammed'e teslim çağrısında bulunmuş olsa da, aldığı menfi cevap üzerine saldırıya geçmiş ve isyanı kanlı şekilde bastırmıştır.

Müellif isyanın başarıya ulaşamamasının sebeplerini maddeler halinde ele almıştır. Öncelikle siyasî sebepler üzerinde duran Zorlu Mansûr'un isyanı haber alır almaz gerekli önlemleri almaya başladığını savunmuştur. Mansûr kadar sistemli önlemler alamayan hatta Medine'nin etrafına kazdırmayı planladığı hendeği dahi tamamlayamayan Muhammed'in birde minbere çıkıp insanları kendisiyle birlikte kalmak konusunda serbest bırakması çatışma esnasında ihtiyaç duyulacak olan insan gücünden de mahrum kalmasına sebep olmuştur. Mansûr'un Alioğulları taraftarlarının yoğun olduğu Kûfe'yi kapatması da Muhammed'i zor durumda bırakmıştır.

Başarısızlı̆ıın askerî sebepleri altında merkezî ordunun tecrübeli askerlerden oluştuğunu belirten müellif askerlerin Horasân menşeli olduklarının da mühim olduğunu savunmuştur. Ona göre Arap askerler Medine'ye ve Ehl-i Beyt'e saldırmak konusunda gevşeklik gösterebilirlerdi. Fakat Horasânlı askerlerin böyle bir hassasiyeti bulunmamakta idi. Muhammed'in taraftarları arasında kabile taassubuna dayalı bir anlaşmazlığın çıkmasını sosyal sebeplerin altına dâhil eden müellif başarısızlı̆̆ın dinî sebepleri altında Muhammed'in bazı hassasiyetlerini dile getirmiştir.

Zorlu'ya göre Muhammed'in isyanı ile birlikte Hasan ve Abbasoğulları arasındaki çatışmalar zirveye ulaşmıştır. Ayrıca halîfe uykularını kaçıran ve geniş kitlelerin de desteklediği bir isyanı bastırmaya muvaffak olmuştur. İsyanın bastırılmasından yaklaşık beş yıl sonra Muhammed'in amcaoğlu Hasan b. Zeyd'i isyana destek vermediği gerekçesiyle Medine valiliğine tayin eden Mansûr böylece düşman ve dostlarına reva gördüğü muameleyi de ortaya koymuştur. 
Dönemin diğer bir isyanı ise Muhammed'in kardeşi olan İbrahim b. Abdullah'ın isyanıdır. Müellife göre Muhammed ve İbrahim kardeşlerin isyanları aslında aynı zamanda başlatılacak tek bir isyandan ibaret idi. Fakat İbrahim'in gecikmesi veyahut Muhammed'in erken davranması farklı bölgelerde ve aynı zamanda ortaya çıkacak olan isyan hareketinin etkisini kırmıştır. Kaynaklar isyanların eşzamanlı başlamaması hakkında muhtelif görüşler barındırmaktadır. Muhammed'in mevcut baskılardan bunalarak isyanı erken başlattığını iddia eden rivayetlerin yanında, İbrahim'in hastalığı veyahut izdivacı sebebiyle geç kaldığı da belirtilmiştir. Zorlu mevcut rivayetleri birleştirerek Muhammed'in mevcut baskılardan sıkılarak belirlenen tarihten evvel harekete geçtiğini, kardeşi İbrahim'in ise o esnada hasta olması sebebiyle geciktiğini savunmuştur.

Basra'da isyanını ilan eden İbrahim b. Abdullah Mansûr'un valisi Süfyan b. Muaviye tarafından desteklenmiştir. Halîfe tarafından gönderilen birlikleri etkisiz hale getiren İbrahim bir ay gibi kısa bir dönemde civar bölgeleri de kendine bağlayarak büyük bir nüfuza erişmiştir. Merkezî orduların farklı bölgelerde patlak veren isyanları bastırmakla meşgul olmaları İbrahim'e müdahaleyi zorlaştırmıştır. Fakat Mansûr'un dirayetli ve sabırlı yapısı, yine görevlerini başarıyla sonlandıran orduların İbrahim'e karşı sevk edilmesi tarafların arasında cereyan edecek büyük hesaplaşmayı kaçınılmaz kılmıştır.

Basra dişındaki Bâhamrâ'ya yaklaşık 100 bin kişiyle ulaşan İbrahim’in karşısına 18 bin kişilik bir kuvvetle İsâ b. Musâ çıkmıştır. İbrahim sayıca üstün olmasına ve karşılaşmanın ilk safhalarında galip gelmesine rağmen mağlup edilmiş ve canından olmuştur.

Cem Zorlu, İbrahim'i başarısızlığa sürükleyen sebepleri maddeler halinde ele almıştır. İbrahim'in iyi bir komutanın meziyetlerine sahip olmadığını ve daha savaş öncesindeki hatalı istişarelere herhangi bir müdahalede bulunmayıp ordusunu yanlış yönettiğini savunan müellif, karşıdaki rakibin Mansûr gibi seçkin bir lider olduğunun unutulmaması gerektiğini vurgulamıştır. Cem Zorlu ayrıca İbrahim b. Abdullah'ın söz ve fiillerinin uyuşmadığını savunmuştur. İbrahim'in mevcut idareye başkaldırmış olmasına rağmen kan dökmeyi sevmediğini ifade etmesi müellifin iddiasını haklı çıkaracak mahiyettedir. Yine isyancıların farklı dinî ve sosyal gruplara mensup olmalar1 -dolayısıla ortak bir menfaat sahibi olmamalar1- ve İbrahim'in kapsamlı bir isyanı tertip edecek kadar vaktinin olmaması mağlubiyetin sebepleri arasında zikredilmiştir.

Zorlu'ya göre Muhammed ve İbrahim kardeşlerin mağlup olmalarındaki esas amil isyana farklı mekânlarda ve eşzamanda başlayamamaları olmuştur. Zira İbrahim'in isyanının dahi tek başına devletin varlığını tehlikeye sokabilecek dereceye ulaşması müellifin iddiasını destekler mahiyettedir. 
Müellif Şii kaynaklı isyanların neticesinde sadece isyancı liderlerinin değil, aynı zamanda Hasanoğulları'nın birçok öncü şahsiyetinin de tasfiye edildiğini savunmuştur. Yine o dönemde inşa faaliyetleri süren Bağdat şehrinin mezkûr isyanlar sebebiyle geciktiğini iddia eden müellif, Mansûr'un bu isyan hareketlerini bastırmış olması sebebiyle "Mansûr" lakabını aldığını ifade etmiştir.

Çalışmasının son bölümünü “Diğer İsyanlar” başlı̆̆ıyla ele alan müellif bu k1sımda genel itibariyle küçük çaplı isyanları ele almıştır. Emevî devletini ihya etme gayretleriyle isyan eden Osman b. Surâka el-Ezdî ve mensubu olduğu Hıristiyanları bir araya getirip kendini kral ilan etme teşebbüsünde bulunan Bündâr gibi isyancıların bulunduğu bu bölümdeki en mühim faaliyet şüphesiz Medine'deki isyan hareketidir.

Muhammed b. Abdullah'ın isyanının bastırılmasından sonra Medine bölgesinde bulunan Horasânlı askerler bölge esnafına satın aldıkları malların ödemesini yapmıyorlar veyahut eksik ödüyorlardı. Bu durumdan rahatsız olan esnaf ahalisi şikâyetlerini valiye arz etmiş, fakat müspet bir karşılık alamamışlardır. Horasanlı bir askerin kasaptan aldığı eti ödemediği gibi bir de kendisine itiraz eden esnafi tehdit etmesi bardağı taşıran son damla olmuştur. Bir araya gelen esnaf evvela bu askeri, ardından ellerine geçirdikleri diğer askerleri öldürmeye başlamış, hatta gelişen hadiseler üzerine Medine valisi ve askerler şehri terk etmek zorunda kalmışlardır. İsyancıların hapishanedeki mahkûmları salıvermeleriyle Muhammd b. Abdullah isyanının destekçilerinden olması hasebiyle suçlu bulunan İbn Ebî Sebra da serbest kalmıştır. Olanları işiten Sebra daha ellerindeki zincirlerle birlikte mescide gitmiş ve Medine'nin önde gelenlerine hitap ederek bu işten derhal vazgeçilmesini istemiştir. İbn Ebî Sebrâ Mansûr'un isyanlar karşısındaki tutumunu tecrübe ettiği için halka nasihatte bulunmuş ve şehir ahalisi ona kulak vermiştir.

Sonuç itibariyle Medinelilerin başlattığı bir isyan yine kendileri tarafından sona erdirilmiş, yine halkın şikâyetlerine kulaklarını tıkayan eski vali halîfe tarafından azledilmiştir.

Cem Zorlu çalışmasının "Sonuç" kısmında ele aldığı isyanlar hakkında genel çıkarımlarda bulunmuştur. Mansûr dönemi isyanların genellikle merkezden ve Arapların meskûn olduğu bölgelerden uzak yerlerde gerçekleștiğini ifade eden müellif, uzak bölgelerde baş gösteren karışıklıkları bastırmanın daha güç olduğunu ifade etmiştir. Zorlu isyanların başarı ile bastırılmasının en temel sebebi olarak Mansûr'un zeki stratejilerine ve azmine işaret etmiștir. Zira halîfe bir isyanı haber alır almaz izlenilecek yöntemle alakalı derhal istişarede bulunur, kararını kat'i surette uygulamaya geçirir ve uzun vadede kontrol altına alınamayan isyanlara dahi yılmadan müdahale ederdi. Müellif devleti en çok meşgul eden ve neredeyse yıkılmasına sebep olacak isyanların Şii faaliyetleri olduğunu belirtmiş ve bu başkaldırıları bastırmaya muvaffak olan halîfeye "Mansûr" lakabının verilmiş olduğunu ifade etmiştir. 
“Abbâsîlere Yönelik Dinî ve Siyasî İsyanlar” başlı̆̆ıyla kaleme alınan çalışmanın kaynakları ağırlıklı olarak doğulu müelliflerin eserlerinden oluşmaktadır. Buna rağmen konuyla ilgili araştırmalarda bulunan batılı yazarlardan da istifade edilmiştir. Araştırmayı değerli kılan noktalardan biri isyanlarından bahsedilecek olan bir fırkanın evvela oluşum ve gelişim sürecinden bahsediliyor olmasıdır. Böylece okuyucu isyancı fırkanın geçmişi ile alakalı bilgiler edinmekle birlikte çoğu zaman onları isyana teşvik eden sebepleri de daha iyi kavramaktadır. Eserin tamamında muhafaza edilen sistematik başlıklar eseri önemli kılan diğer bir husustur. Cem Zorlu konu edindiği isyanları ortaya çıkış sebepleri, gelişimleri, sonuçları gibi başlıklar altında ele almış, özellikle de isyanların başarısız olmalarının sonuçları hakkında maddeler halinde değerlendirmelerde bulunmuştur. Müellifin tarihçiliğin gereği olarak tarihi olayları sebep ve sonuç açısından çoğu zaman kendi yorumlarıyla izaha kalkışması ve okuyucu uzun ve sıkıcı değerlendirmelere muhatap kılmaması öne çıkarılması gereken diğer bir husustur. Fakat kitabı önemli kılan asıl unsur Türkçe kaleme alınan çalışmalar arasında Ebû Cafer el Mansûr dönemini ortaya çıkan isyanlar itibariyle günümüze dek ele alan tek araştırma eseri olmasıdır. 